\title{
Research on Three-part Argumentative Writings for English Majors in China
}

\author{
Luo Mingli ${ }^{1}$ \\ ${ }^{1}$ School of Foreign Languages, Leshan Teachers College, Sichuan, China \\ Correspondence: Luo Mingli, School of Foreign Languages, Leshan Teachers College, No. 778, Binhe Road, \\ Leshan, Sichuan, 614004, China. E-mail: luomingli88@yahoo.com.cn
}

Received: March 7, 2012 Accepted: March 28, 2012 Online Published: July 1, 2012

doi:10.5539/elt.v5n7p140 URL: http://dx.doi.org/10.5539/elt.v5n7p140

This paper is one of the research results of the project sponsored by 2009 Leshan Teachers College Key Research Project "The Research of Planning of Mapping about English Argumentative Writing of Chinese Students'” (Project No. S0903).

\begin{abstract}
Writing is a kind of creative thinking activity. The teaching of Three-part argumentative writing is crucial in college English instruction. Many English majors that fail to write well lack sufficient input of English argumentative reading materials, use Chinese thinking and structure to express their ideas, and lack frequent and sufficient writing practice in English. This paper reviews the application of scaffolding theory and schema theory in writing, and proposes a series of training strategies of blank-filling writing, guided writing, controlled writing, and free writing. Through this series of training that is based on the process approach, the product approach as well as the genre approach, students can gain better writing skills. They can learn how to plan before writing and improve their abilities to write argumentative essays in English effectively.
\end{abstract}

Keywords: low level of free writing, thinking modes, planning before writing, higher level of free writing

\section{Introduction}

English is learned as a foreign language (EFL) in China. English writing is a kind of creative thinking activity as well as a dynamic and interactive process. It is difficult for most Chinese English majors to write arguments in English because of the different language systems, cultural backgrounds and thinking patterns. Some studies show that arguments and expositions written by Western people are typically made up of three parts: the introduction, body, and conclusion, in which topic sentences, supporting sentences, and concluding sentences can be easily found (Bing Xue, 2004; Xuemei Liu, 2008; Xinhua Gao \& Ke Li, 2010). Chinese English writing researchers call this kind of writing method "three-part argumentative writings". They are likely in agreement with the requirements for writing in the TEM-4 and TEM-8, "You are to write in three parts. In the first part, state specifically what your opinion is. In the second part, provide one or two reasons to support your opinion. In the last part, bring what you have written to a natural conclusion or make a summary." However, the teaching of three-part argumentative writing, which is a weak part for English majors in the TEM-4 and TEM-8, is crucial in college English instruction. Jinyan Fan (2008) pointed out that, "Both the colleges and the examinees pay great attention to the TEM-4, but the result is not satisfying... reflected in the structure of the composition, there is not a perfect structure nor a cohesion" (p. 37). The typical errors in writing in the TEM-8 for English majors can be listed as: 1) the argument is not fully expanded; 2) the structure is not rigorous, with no topic sentences in paragraphs or obvious relationships between sentences and paragraphs; 3 ) the beginning and end part of the essay are not in agreement with each other or self-contradictory; 4) the essays lack coherence and logic (Jie Liu \& Hong Chen, 2006). For decades, the teaching of writing at the tertiary level has been product-centered. The emphasis is on "style, organization, and correctness" (Hairston, 1982). However, in an English writing class, both teachers and students ignore the importance of planning before writing. The writing teachers convey theories or rules on how to write argumentative writings, but their students frequently make errors as follows: 1) their writings are not argumentative; 2) their expressions are Chinese-like, without logic, and with many grammar mistakes; 3) the form of their writing is not in agreement with their meaning; and 4) the viewpoints or ideas of students cannot be found in their writing. The biggest problem with EFL writing for English majors in China is that they don't want to write and write too little. When students are asked to write argumentative compositions in class, they always complain about the task of writings 200 words or so within 35 minutes. In fact, 
most students cannot complete the limited-time tasks. In the author's eyes, students very much like to shift the pattern of Chinese narrative writings to English argumentative writings. Take a topic assigned by writing teachers: "Advertisements on TV", as an example. Most students begin their first sentence with "With the development of China's economic, we can now see there are many advertisements on TV." This sentence cannot be regarded as the topic sentence, for it does not contain a theme-rheme structure, which is the "basic form of the organization of the clause as message" (Halliday, 1985, p. 53), and the "basic unit of language in use is not a word or a sentence, but a text" (Halliday, 1970, p. 160). The author's researches show that nearly eighty-five percent of his students do not have the habit of planning before they write. This paper reviews the concepts of planning in writing, the application of scaffolding theory and schema theory in writing, and proposes a series of training strategies of spot writing, guided writing, controlled writing, and free writing. Through this series of training and the teaching of the process approach, the product approach as well as the genre approach, English majors can become better writers. They can plan before writing and improve their ability to write argumentative writings in English effectively.

\section{Theoretical Background}

\subsection{Writing Approaches}

\subsubsection{The Product Approach}

The product approach has its basis in the audio-lingual approach, which was a widely used method of teaching English as second language (L2) in the 1950s and 1960s. The underlying principles behind this approach are that mastery of a language is in speech production, and this is to be achieved by drills and repetition (Silva, 1990). According to Pincas (1982), a proponent of this approach, the learner should internalize fixed patterns of smaller components in sentences before proceeding to larger units of composition or text. With this approach, teachers focus on how students' final product measured up against a list of criteria that included "content, organization, vocabulary use, grammatical use, and mechanical considerations such as spelling and punctuation" (Brown, 1994, p. 320). In this approach, learning to write has four stages: familiarization, controlled writing, guided writing and free writing.

The product approach has its merits as well as shortcomings. The advantages of this approach are: 1) students will have a clear idea about the organization of a particular text, for imitation is one effective way to develop students' vocabulary and structure in writing; 2) It is more useful for practical teaching and does suit the teaching situation in China, where English is taught as a foreign language rather than a native language. However, this approach, which focuses on writing tasks in which students imitate, copy and transform teachers supplied models, is in total teacher-centered and product- or output-focused, and students' creativity is given little consideration. Their development of writing skills is ignored as well.

\subsubsection{The Process Approach}

In the mid-1970s, the process approach, initiated by Graves (1978), began to replace the product approach. The process approach tends to focus more on the varied classroom activities which promote the development of language use; brainstorming, group discussion, and re-writing. As follows:

1) focus on the process of writing that leads to the final written product; 2) help student writers to understand their own composing process; 3) help them to build repertoires of strategies for prewriting, drafting, and rewriting; 4) give students time to write and rewrite; 5) place central importance on the process of revision; 6) encourage feedback from the instructor and peers. (Brown, 1994, p. 320)

The process approach is characterized by its emphasis on the development of writing skills. As its name suggests, in the process approach, the focus of attention has shifted from the finished product to the whole process of writing: prewriting, composing/drafting, revising, and editing (Tribble, 1996).

Compared with the product approach, the process approach has undoubtedly made great improvements in practical teaching. The role of a teacher is more of a facilitator in providing feedback during the process of each student's composition than a didactic instructor. The shift of focus and the change in the teacher's role necessitate greater emphasis on activities such as cooperative group work and peer evaluation. Writing development is seen as an unconscious process which happens when teachers facilitate the exercise of writing skills. However, the disadvantage of the process approach is that it views the process as the same for all writers, regardless of what is being written and who is doing the writing, for it gives insufficient importance to the purpose and social context of the piece of writing (Badger \& White, 2000). This approach requires a long training period, which is not suitable for our present teaching plan. Furthermore, it is common that there are more than 40 students in one class and the teacher cannot give guidance to each student. Therefore, it is not a suitable method to be applied to large classes.

\subsubsection{The Genre Approach}

Since the mid-1980s, considerable attention has been paid to the genre approach of teaching writing. The Routledge 
Encyclopedia of Language Teaching and Learning defines the genre approach as "a framework for language instruction" (Byram, 2004, p. 234) based on examples of a particular genre. In contrast to the process approach, the genre-based approach views writing as a social and cultural practice. This involves not simply teaching activities for a writing process, but also teaching the purpose of writing, the context where the writing occurs, and the conventions of the target community. This approach to teaching writing, as Paltridge (2004) claims, emphasizes the teaching of particular genres students need for later social communication and success. According to Cope and Kalantzis (1993), it consists of three phases: 1) the target genre is modeled for the students, 2) a text is jointly constructed by the teacher and students, and 3) a text is independently constructed by each student. The approach acknowledges that writing takes place in a social situation and reflects a particular purpose, and that learning can happen consciously through imitation and analysis, which facilitates explicit instruction (Badger \& White, 2000).

Relevant genre knowledge is as follows. A genre is chiefly identified by the communicative purpose for which it is created in a particular social context (Swales, 1990). Nunan (1999) explains that different genres of writing "are typified by a particular structure and by grammatical forms that reflect the communicative purpose of the genre" ( $p$. 280). Swales (1990) and Martin (1984) share an essential viewpoint that all genres control a set of communicative purposes within certain social situations and that each genre has its own structural quality according to those communicative purposes (p. 309). Therefore, the communicative purposes and structural features should be identified when genres are used in writing classes. The structural features include both standards of organization structure and linguistic features. Standards of organizational structure refer to how the text is ordered. In the case of a written text or written discourse, various factors impinge upon its production and processing.

\subsection{Application of Scaffolding Theory}

Scaffolding has been used successfully as an instructional technique for many years. The term "scaffolding" was first used by Jerome Bruner in his book Actual Minds, Possible Worlds (1986) to describe the assistance that a teacher gives a student to help him/her safely take risks and reach higher than would be possible by the students efforts alone. Bruner used the term to talk about the way caregivers assist young children in learning by: 1) the joint construction of language; 2) gradually withdrawing their support as children gain independent mastery of the language. Christie (2005) points out that the term scaffold is "a metaphor taken from the building industry. It refers to the way scaffolds sustain and support people who are constructing a building. The scaffolds are withdrawn once the building has taken shape and is able to support itself independently" (p. 42-43).

Hammond and Gibbons (2001) note that "A major feature of the term 'scaffolding' is its ability to capture the role of the 'expert,' or more knowledgeable other (typically the teacher), in assisting students' learning, and the role of that knowledgeable other in extending students' current levels of understanding or current capabilities." A scaffolding experience allows a student to move away from assistance and to become an independent learner able to transfer the acquired knowledge to new contexts. Given this premise, a teacher must recognize when to withdraw support and to move intentionally away, allowing the student to apply and transfer knowledge in new ways. Scaffolding is also seen in instructional design as the intentional planning of curricula to organize tasks and activities in such a way as to build understanding. Thus, scaffolding occurs at both the micro (the individual teacher/student interaction) and the macro (the program or organization) level, and both elements are presumably active in learning environments where good pedagogy takes place.

Scaffolding is therefore important in writing instruction. Strong instructional programs recognize the need to design curricula that purposefully builds knowledge, introducing skills and concepts in logical and meaningful increments that provide students a firm, factual foundation of content. Teachers in the program must be adept at scaffolding at the micro level by providing instruction and assistance that challenges and motivates individual students to construct and transfer new knowledge and understanding.

\subsection{Application of Schema Theory}

Bartlett $(1932,1958)$ first proposed the concept of schema or schemata (plural). He suggested that memory takes the form of schema, which provides a mental representation or framework for understanding, remembering and applying information. Rumelhart (1980) further developed the schema concept and described schema theory as basically a theory of how knowledge is mentally represented in the mind and used. Schemata are created through experience with the world and the person's culture, which includes interactions with people, objects and events within that culture. Schema theory can help us to focus on the prior knowledge and experience, or mental schema, that students bring to the learning situation, and the gaps or discrepancies between what the learner already knows and what he/she needs to know to successfully carry out and complete the particular learning task. Students who are limited by their experiences and do not have relevant schemata have difficulty carrying out the task successfully, and hence teachers need to help students develop and fine-tune the appropriate conceptual systems that are needed to 
successfully complete the learning task(s).

In the 1970s, however, the schema construct was reintroduced into psychology through the work of the computer scientist Marvin Minsky. Minsky was attempting to develop machines that would display human-like abilities (e.g., to perceive and understand the world). In the course of trying to solve these difficult problems, he came across Bartlett's work. Minsky concluded that humans were using their stored knowledge about the world to carry out many of the processes that he was trying to emulate by machine, and he therefore needed to provide his machines with this type of knowledge if they were ever to achieve human-like abilities. Minsky developed the frame construct as a way to represent knowledge in machines. Minsky's frame proposal can be seen as essentially an elaboration and specification of the schema construct. He conceived of the frame knowledge as interacting with new specific information coming from the world. He proposed that fixed generic information be represented as a frame comprised of slots that accept a certain range of values. If the world did not provide a specific value for a particular slot, then it could be filled by a default value.

\subsection{Argumentative Writings for TEM-4 and TEM-8}

TEM (Test for English Majors) is a particular EFL (English as a Foreign Language) test in China. It was set up by the former State Education Commission in 1991, and has been organized by the Higher Education Institution Foreign Language Major Teaching Supervisory Committee since then. It was set to test the actual performance of the Higher Education Institution English Major English Teaching Syllabus (Higher Education Institution Foreign Language Teaching Supervisory Committee English Group, 2000). There are two levels in the TEM, the TEM-4 and the TEM-8. TEM-4 is for sophomore students, while the TEM-8 is for higher level students. The tests are meant for English majors when they are in their second and fourth year, or more specifically, in their fourth and eighth term, which is why the tests are called the TEM-4 and the TEM-8. They mainly test students' ability to use English as a foreign language.

The genres of the TEM- 4 and the TEM- 8 writings are mostly argumentative, and the requirements for the TEM- 4 and the TEM-8 are nearly similar to each other, except for the length of number of words. The directions for the TEM-4 are as follows: You are to write in three parts. In the first part, state specifically what your opinion is. In the second part, provide one or two reasons to support your opinion. In the last part, bring what you have written to a natural conclusion or make a summary. The directions for the TEM-8 are as follows: In the first part of your essay you should state clearly your main argument, and in the second part you should support your argument with appropriate details. In the last part you should bring what you have written to a natural conclusion or make a summary. Obviously, we can see that the styles for both the TEM-4 and the TEM- 8 are argumentative writings, which are written in three parts. The writers should state clearly their main argument in the first part, provide appropriate reasons or details to support their argument in the second part, and bring a natural conclusion or make a summary in the third part. Scores for both the TEM-4 and the TEM- 8 are based mostly on content, organization, language (grammar for the TEM-4) and appropriateness. The differences are that the TEM-4 has a composition of about 200 words, while the TEM- 8 has a composition of about 400 words; argumentative writing in the TEM- 4 is worth $15 \%$ of the test grade, while in the TEM- 8 it is worth $20 \%$ of the total grade.

The criteria of evaluations for argumentative writings for both the TEM- 4 and the TEM- 8 are almost the same, but with different scores. Take Band 5 (Score 15-13 for the TEM-4; Score 20-18 for the TEM-8) and Band 1 (Score 3-0 for TEM-4; Score 8-6 for TEM-8) for example. For Band 5, 1) the writing effectively addresses the writing task; 2) it demonstrates a well developed logical organizational structure with clearly stated main ideas and sufficient supporting details; 3) it has almost no errors of vocabulary, spelling, punctuation or syntax, and it displays an adequate ability to use the language with appropriacy; 4) no difficulty is experienced by the reader. For Band 1, 1) the writing almost completely fails to address the writing task; 2) it has neither an organizational structure nor coherence; 3) Almost all sentences contain errors of vocabulary, spelling, punctuation or syntax, and it displays no ability to use the language with appropriacy; 4) even after considerable effort on the part of reader, the text is largely incomprehensible (Yanli Zhang \& Mingwei Pan, 2010, p. 4-5; Ren Huang, 2011, p. 1-2). Since 2009, the new grading standards of argumentative writings for the TEM-4 have been followed by three dimensions of ideas and arguments, language use / control, and mechanics / orthographic conventions based on five grades (excellent, very good, fair, poor, and very poor). Namely, it is mainly focused on relevant content, logical structure, coherent organization, correct grammar, fluent language, and appropriate expression. The focuses of argumentative writings for the TEM-8 are on fluent language, appropriate expression, reasonable structure, appropriate style, and persuasive reasoning.

Frankly speaking, in recent years, upon reflecting on the TEM-4 and TEM-8 scores the students have acquired, the author clearly learns that there is still a lot of room for improvement, especially when it comes to argumentative 
writings. Some students still find it tough to put a pen to paper and work out a satisfactory argumentative writing; some are hard-pressed to express themselves smoothly in writing. It is a fact that success comes from writing according to an expected English-style structure, giving support for their topic sentence, and using English in a grammatically correct way. English majors need some writing approaches and methods such as the product approach, the process approach, the genre approach, scaffolding theory, and application of schema theory to aid them in their argumentative writing in the TEM-4 and TEM-8.

\section{Strategies of Training}

\subsection{Blank-filling Writing}

The theory of blank-filling (gap-filling) writing dates to the schema theory. Schema can be categorized as: formal schema and content schema. The writing schema serves as a good introduction to the idea, and requires the use of both formal and content schema. For foreign language learners, the content schema comes before the formal schema. With the development of students' foreign language competence and accumulation of knowledge, the content schema can gradually change, enrich, and renew; the formal schema such as regularities and styles, based on drills, can be autonomous from the three stages of cognition, association, and autonomy. Writers need to pay more attention to the unity, coherence, conciseness, and regularities of English expression.

Blank-filling writing is effective and helpful for students to construct the frame of argumentative writing. As English majors, they have read many argumentative writings, which helps them imitate the samples.

\section{A Few Remarks on Competition}

Competition is a common phenomenon in our social life. We compete when we ..., we try to do ..., and there is constant competition for ..., and so forth. We can say that competition is one of the motivating forces of the development of society.

We often find competition and cooperation at the same time. Think of a basketball game, .... But each member of the team .... In most cases, we can't have competition without cooperation. Thus they are equally important.

While we are advocating competition, we can't forget cooperation. Nothing is to be carried to extremes. Pure and exclusive competition leads to failures. ... especially in modernizing our country. So competition and cooperation are equally important.

The important thing for three-part argumentative writing is to learn to help students communicate their ideas clearly and logically. They will be trained how to write clearly, accurately, and logically, with the emphasis on effective presentation of facts and opinions, using blank-filling writing. The tasks set all have a "real" purpose and a particular reader in mind. Examiners assess the range and accuracy of language, appropriacy, organization and task achievement.

\subsection{Guided Writing}

Guided writing involves the teacher working with small groups of students. In guided writing students apply the knowledge they have gained from modeled and shared writing sessions, with varying degrees of support from the teacher. The students explore aspects of the writing process, which have been demonstrated. The teacher predetermines the teaching focus from observations and analysis of students' writing. The session is focused on specific aspects of writing that students need to develop.

Hill (1999) explains guided writing in her book Guiding Literacy Learners, as follows:

Guided writing involves individuals or small groups of students writing a range of text types. The teacher may provide short mini-lessons to demonstrate a particular aspect of text type, grammar, punctuation or spelling. Guided writing is linked to reading and various text types are used as models. Students may use writing frames or templates as scaffold for writing.

David Hornsby (2000) outlines two different ways that guided writing can be managed. Each approach has a different main purpose.

1) One or two sessions may be planned for small groups of children who need assistance with specific writing skills;

2) Many sessions, building upon shared reading and writing of a particular genre, are planned. Firstly, the children are immersed in the genre during reading. Secondly, they compose a text in that genre during shared/interactive writing. Finally, they are guided to write their own text in that genre.

Guided writing is useful for a range of teaching purposes, which will vary, depending on the developmental stage and the needs of the students. Guided writing uses effective guided instruction methods to build the strong scaffolding needed for students to learn, master, and enjoy the craft of writing. The following example based on the 
outline can show the approach to guided writing.

\section{On Honesty}

You are to write three parts. In the first part, state what honesty means to you. In the second paragraph, state the reasons for its importance. In the last paragraph, compare it with dishonesty.

Paragraph 1: Honesty means speaking the truth and being fair and upright in act. 1) Considered as a virtue, ... 2) One who lies and cheats, ... 3) Dishonesty is generally, ...

Paragraph 2: As ...says, "Honesty is the best policy." 1) If ... (importance of honesty) 2) People ... (attitudes toward honest and dishonest people) 3) If ... (importance to success) 4) Therefore ... (conclusion).

Paragraph 3: Many people, however, try various dishonest means in order to get what they want. 1) For ... (example: by bribery or lies) 2) Some ... (example: plagiarism in academic works) 3) Others ... (example: cheating in exams) 4) ... (your attitude toward this).

\subsection{Controlled Writing}

Controlled writing means that students' writing is limited to a special field. The value of teaching controlled writing in the beginning of the acquisition of writing skills is undisputed. Basic to composition skill is control of sentence structure and accuracy in mechanics. The following outline can show the teacher how to train his students to write a three-part argumentative essay based on the approach to controlled writing.

\section{A Major Advantage/Disadvantage of Advertising on Television}

Thesis: $T V$ is the most effective medium for advertising.

\section{I. $T V$ is the most popular medium that reaches almost every family.}

a. Computers: expensive, not needed by every family.

b. Newspapers and magazines: not subscribed by every family.

\section{TV commercials are best remembered with sound, pictures and actions.}

a. Newspapers and magazines: words but no sound and actions.

b. Radios: sound but no pictures and actions.

\section{TV commercials are rarely missed.}
a. Arranged between hot shows.
b. Appearing at best time of day.
c. Seen at random.

Conclusion: To achieve the best effect of advertisements, business organizations should promote their products and services on $T V$.

Controlled writing can, to some extend, help students to focus on the theme rather than beyond the topic. As Ross (1968) mentioned, acquiring skill in composition involves acquiring control over rhetorical devices-setting up a central idea, maintaining this idea throughout the composition, presenting the material in orderly sequence, and so on. Basic to composition skill is control of sentence structure and accuracy in mechanics so that the student writes correctly the first time and does not practice errors. Control over sentence structure can be exercised by a number of different devices, most of which involve imitation of some kind (p. 253). The author once gave his students the title: Is It Wise to Make Friends Online? and asked them to make the first draft following the below schema within 20 minutes.

\section{Is It Wise to Make Friends Online?}

Thesis: Making friends online is not wise.

\section{Making friends online is one of the heated topics among college students.}

a. Some people: wise; the others: not wise.

b. My idea: not wise.

II. The reasons for making online is not wise are as follows..

a. it is not safe for us to do ...

b. it is not helpful for us to do... 
c. it is not useful for us to do ...

III. It is not wise to make friends online.

$$
\begin{aligned}
& \text { a. ... } \\
& \text { b. ... } \\
& \text { c. ... }
\end{aligned}
$$

Conclusion : Making friends online is not wise, for it is not safe, or helpful for ..., nor useful for ...

The result was that most students could finish the task within 15 minutes, and spoke about their paper in class. They thought that it was a good way to voice writing ideas, construct text frames, organize content materials, consider language expression, and form the habit of thinking effectively.

\subsection{Free Writing}

Free writing is that euphoric stage where the student has mastered sufficient language skills and organization to be able to handle the writing of a chosen topic when given only a specific amount of time and a definite length. It helps the student discover ideas and gather materials. It also is an exercise in which he writes quickly off the top of his head with no judgment intended. It is useful, on occasion, for getting a writing project started, but it is also the most common warm up exercise used by professional writers. For English majors, they may try focused free-writing. It requires them to think about the topic as they get ready. After that, all they need to do is follow the free writing procedure as has been outlined. The advantages of free forming conception writing can be listed as: 1) it increases fluency if writers do it regularly; 2) it strengthens the right brain over time; 3) it warms up the brain for higher level activity; 4) it often reveals good ideas which have not previously been thought of for either writing or maybe living. The following is writing directions for the 2011 TEM-4:

Recently government agencies in some big cities have been studying the possibility of putting a "pollution tax" on private cars. The amount of tax private car owners would have to pay would depend on the emission levels, i.e. engine or vehicle size. This has caused quite a stir among the public. Some regard it as an effective way to control the number of cars and reduce pollution in the city. But others don't think so. What is your opinion?

Write a composition of about 200 words on the following topic: Should Private Car Owners Be Taxed for Pollution?

This test is not so difficult for English majors to write well, for this kind of topic is very familiar to them. If English writing teachers, as usual, give students some topics like The Choices of Transportation: Bicycles or Private Car? Or My ideas about Environment Protection Or My Suggestions about Tax, and so on, students can easily construct their thesis, writing logic, controlling idea, writing frame, topic sentences, supporting sentences, and concluding sentences as well as paragraph development, and language expressions. As Xiajun Zhao (2007) said, English writing teachers should lecture students about some writing pedagogies and skills in class, and students should do more writing exercises after class. It is proven that weekly essay assignments, free-writing and keeping diaries somehow work with overcrowded Chinese classes and make the students write often and it helps them improve their writing skills and make more progress in argumentative writing later on. The author has taught English writing courses for English majors since 2005 and guided his students from lower level blank-filling writing to higher level writing based on writing theories and skills. The students' scores in Item Writing are 1.76 points higher than the national average of the TEM-4.

\section{Conclusion}

English is learned as a foreign language (EFL) in China. The biggest problem with EFL writing for English majors is that students don't want to write and write too little. Writing is isolated from the other language skills of listening, speaking, and reading; there is very little social interaction. More Chinese students have got the habit of thinking in Chinese, which hinders sufficient comprehensive input. Based on the analyses of the Scaffolding Theory, Schema Theory and the three approaches to writing - the process approach, the product approach as well as the genre approach to writing, English majors can foster awareness of planning before the three-part argumentative writing through a series of training strategies like blank-filling writing, guided writing, controlled writing, and free writing, which is called the highest level of three-part argumentative writing. This series of training show students' development of three-part argumentative writing from mechanical imitation to autonomous acquisition, from form to content, from low level free writing without planning before writing to higher level free writing.

\section{References}

Badger, R. G., \& G. White. (2000). A process genre approach to teaching writing. ELT Journal, 54(2), 153-60. 
http://dx.doi.org/10.1093/elt/54.2.153

Bartlett, F. C. (1932). Remembering: An experimental and social study. Cambridge: Cambridge University Press.

Bartlett, F. C. (1958). Thinking. New York: Basic Books.

Bing Xue. (2004). The New Concept of English Writing. College Times, (06), 44-46.

Brown, H. D. (1994). Teaching by principles: An interactive approach to language pedagogy. Englewood Cliffs, NJ: Prentice Hall Regents.

Brown, H. D. (2001). Teaching by Principles: An Interactive Approach to Language Pedagogy. Beijing: Foreign Language Teaching and Research Press.

Bruner, J. (1986). Actual Minds, Possible Worlds. Harvard UP.

Byram, M. (2004). Genre and genre-based teaching. The Routledge Encyclopedia of Language Teaching and Learning (pp. 234-237). London: Routledge.

Christie, F. (2005). Language Education in the Primary Years. Sydney: University of NSW Press.

Cope, B., \& M. Kalantzis. (eds.). (1993). The powers of literacy: A genre approach to teaching writing. Pittsburgh, PA: University of Pittsburgh Press.

Graves, D. H. (1978). Balance the Basics: Let Them Write. New York: Ford Foundation.

Hairston, M. (1982). The winds of change: Thomas Kuhn and the revolution in teaching of writing. College Composition and Communication, 33(1). http://dx.doi.org/10.2307/357846

Halliday, M. A. K. (1970). Language Structure and Language Function. In J. Lyons (ed), New Horizons in Linguistics. Harmondsworth: Penguin.

Halliday, M. A. K. (1985/1996). An Introduction to Functional Grammar (2nd ed.). London: Edward and Arnold.

Hammond, J., \& P. Gibbons. (2001). What is Scaffolding? In Hammond (ed.), Scaffolding: Teaching and Learning in Literacy Education. Sydney: Primary English Teaching Association.

Higher Education Institution Foreign Language Teaching Supervisory Committee English Group. (2000). Higher Education Institution English Major English Teaching Syllabus. Beijing: Foreign Language Teaching and Researching Press.

Hill, S. (1999). Guiding literacy learners; focus on literacy. Armadale, Victoria: Eleanor Curtain.

Hornsby, D. (2000). A Closer Look at Guided Reading. Armadale, Victoria: Eleanor Curtain.

Jie Liu, \& Hong Chen. (2006). Errors in Writing in TEM8 and Teaching Strategies. Journal of Jiangxi Institute of Education, (02), 59-62.

Jinyan Fan. (2008). An Exploration of the TEM-4 Writing Mode. All Circles (Technology and Education), (2), 37-38.

Martin, J. R. (1984). Language, register and genre. In F. Christie (ed.), Children Writing. Geelong Victoria: Deakin University Press.

Minsky, M. (1970). Form and Content in Computer Science (1970 ACM turing lecture), Journal of the ACM (JACM), 17(2), 197-215. http://dx.doi.org/10.1145/321574.321575

Nunan, D. (1999). Second language teaching and learning. Boston: Heinle and Heinle Publishers.

Paltridge, B. (2004). Approaches to teaching second language writing. 17th Educational Conference Adelaide 2004. http://www. Englishaustralia.com.au/ea_conference04/proceedings/pdf/Paltridge.pdf. (Retrieved 20/09/, 2006).

Pincas, A. (1982). Teaching English Writing. London and Basingstoke: Macmillan Publishers.

Ren Huang. (2011). Standard Model and Recitation for TEM-8. Chuangchuen: Jilin Publishing Group Ltd.

Ross, J. (1968). Controlled Writing: A Transform ional Approach. TESOL Quarterly, 2(4):253-261. http://dx.doi.org/10.2307/3585922

Rumelhart, D. E. (1980). Schemata: The building blocks of cognition. In R. J. Spiro, B. C. Bruce \& W. F. Brewer (eds.), Theoretical issues in reading and comprehension. Hillsdale, NJ: Lawreence Erlbaum Associates.

Silva, T. (1990). Second Language composition instruction: developments, issues and directions in ESL. In B. Kroll (ed.), Second Language Writing: Research insights for the classroom. Cambridge: Cambridge University Press.

Swales, J. (1990). Genre Analysis. Cambridge: Cambridge University Press. 
Tribble, C. (1996). Writing. Oxford: Oxford University Press.

Xiajun Zhao. (2007). Reflect on the Teaching of English Writing Results from TEM-4. Journal of Inner Mongolia Normal University (Educational Science), 20(1), 128-130.

Xinhua Gao, \& Ke Li. (2010). Fostering Several Awareness in English Writing. Journal of Teaching and Management, (09), 79-80.

Xuemei Liu. (2008). Training and Exploring "Soft Skills" in English Writing Class. The Science Education Article Collects, (10), 177/179.

Yanli Zhang, \& Mingwei Pan. (2010). English Writing for TEM-4. Dalian: Dalian University of Technology Press.

\section{Author}

Luo Mingli: associate professor of Leshan Teachers College; Research fields: English pedagogical theory and practice, English writing, higher normal education research; Address: School of Foreign Languages, Leshan Teachers College, Leshan Sichuan, China; Postcode: 614004. 